\title{
Research on the Coordinated Development of Logistics Economy and Ecological Environment in Anhui Province
}

\author{
Wenjing Hao \\ School of Business Administration, Anhui University of Finance and Economics, Bengbu, China \\ Email: 15835236170@163.com
}

How to cite this paper: Hao, W. J. (2021). Research on the Coordinated Development of Logistics Economy and Ecological Environment in Anhui Province. Open Journal of Social Sciences, 9, 469-478.

https://doi.org/10.4236/jss.2021.94035

Received: March 25, 2021

Accepted: April 26, 2021

Published: April 29, 2021

Copyright $\odot 2021$ by author(s) and Scientific Research Publishing Inc. This work is licensed under the Creative Commons Attribution International License (CC BY 4.0).

http://creativecommons.org/licenses/by/4.0/

\begin{abstract}
With the rapid development of China's economy, the logistics industry plays a supporting role while the impact on the ecological environment is more and more obvious. This paper mainly studies the relationship between logistics economy and ecological environment in Anhui Province, selects the data of Anhui Province from 2010 to 2018, uses MATLAB, SPSS and other software to process and calculate, and analyzes and evaluates the coordination degree of its development through the synergistic degree model of composite system. The results show that the synergistic development level of the two is concentrated in the middle and generally presents an M-shaped fluctuation, which is at a low level of synergistic degree. In the end, rationalization suggestions are put forward for the future development of logistics industry in Anhui Province in order to further promote the coordinated development of logistics economy and ecological environment.
\end{abstract}

\section{Keywords}

Logistics Economy, Ecological Environment, Entropy Method, Composite System, Collaborative Development

\section{Introduction}

With the positive guidance of the national policy, the rapid growth of the logistics industry at the same time the scientific concept of development has gradually become popular. Adhering to the concept of "green water and green mountains are gold and silver mountains", more and more production enterprises, sales enterprises and logistics companies began to respond to the call of green logistics, actively assume social responsibilities, and develop and apply new technologies of green logistics with intelligent algorithms as the core. Nowadays, the 
development mode at the expense of the ecological environment has been eliminated. One of the goals of the logistics industry is to achieve green logistics. The $14^{\text {th }}$ Five-Year Plan mentioned that we should adhere to the implementation of sustainable development strategy, regional major strategy and regional coordinated development strategy, and promote the comprehensive green transformation of economic and social development. In the "Implementation Opinions on Further Reducing Logistics Cost", it is proposed that a scientific, eco-friendly, clean, low-carbon, intensive and efficient green transportation system should be initially built by 2020 . China's logistics industry is developing towards a new direction of green, intelligent and efficient.

S. L. Lan and Ray Y. Zhong (Lan \& Zhong, 2018) believe that one of the possible ways to achieve sustainable development is the coordinated development of logistics and economy, and analyze the key factors that affect the coordinated development of urban economy and logistics. Liang Wen et al. (Liang Wen et al., 2018) established the evaluation index system and dynamic coupling model of regional logistics and economic system in Wanjiang urban belt, and found that it reached a highly coordinated state for the first time in 2015. Li Hong and Li Lei (Li Hong \& Li Lei, 2019) selected the three economic circles of Bohai Rim, Yangtze River Delta and Pearl River Delta to make a comprehensive evaluation of them and explore the coordinated development level of the composite system. Xia Yeling et al. (Xia Yeling et al., 2017) constructed the evaluation index of ecoeconomic system synergy degree of resource-based cities and comprehensively measured the eco-economic system synergy degree of Huainan City, and the results showed that the synergy degree was generally at the level of non-synergy or low synergy.

Through the review of the previous literature, it is found that the research of scholars mainly focuses on the ability to evaluate the competitiveness of regional logistics economy, and there are relatively few research literatures that combine logistics with ecological environment, which has a negative impact on the formation of ecological compensation mechanism. Therefore, based on the Chinese Bengbu in Anhui province as the research object, using the entropy weight method value method to quantitatively calculate the weight of each index, based on the use of complex system coordination degree model of comprehensive measure logistics economy and ecological economy system on the synergy degree in anhui province, on the basis of three aspects from the government, enterprise and society public put forward suggestions and countermeasures, to improve the coordinated development of eco-economic system in Anhui province has important practical significance.

\section{Establishing Evaluation Index System Based on Entropy Weight Method}

\subsection{Data Source and Indicator Selection}

All data in this article are from the Anhui Provincial Bureau of Statistics, China. 
In the collection of relevant index data from 2010 to 2018, the transportation industry and the post and telecommunications industry were regarded as the logistics industry, and the multiple interpolation method was adopted to fill in the missing data by SPSS software. By referring to scholars' research literature and relevant materials, combined with the relevant policy documents of Anhui Province on logistics economy construction and ecological environment construction,the factors affecting the comprehensive synergy degree of logistics economy and ecological environment in Anhui Province are determined as shown in Table 1.

The evaluation index system of logistics economy subsystem includes three parts: economic development, logistics scale and information construction. Economic development reflects the development degree of regional logistics and reflects its economic strength; The scale of logistics reflects the scale of regional logistics infrastructure and its role in promoting economic development. The informationization level is the key factor of regional logistics development. The

Table 1. Index system of coordinated evaluation of logistics economy and ecological environment.

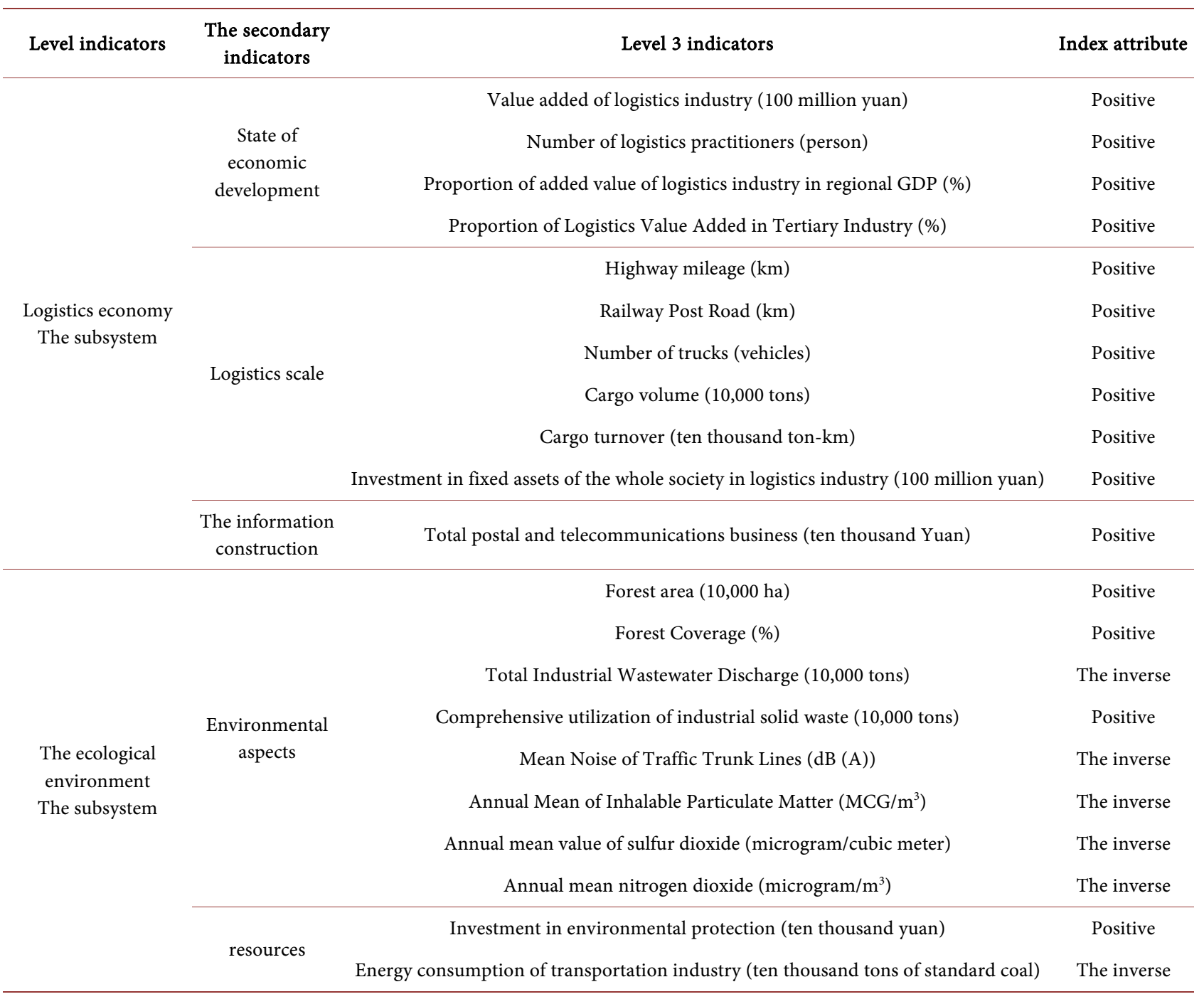


evaluation index system of ecological environment subsystem includes two aspects: environment index and resource index. Environmental indicators reflect the impact of regional logistics development on ecological environment; Resource is the material base of regional logistics development, and resource index reflects the degree of resource utilization by regional logistics.

\subsection{Maintaining the Integrity of the Specifications}

Entropy weight method is an objective weighting method, which determines the weight of each index through the uncertainty of the information provided by each index, and then obtains the information of each index. The larger the value is, the greater the degree of disorder, and the greater the influence of the index on the subsystem in which it is located (Lu Qinghua \& Liu Wei, 2020). Therefore, we can use the information to complete the calculation of index weight with the help of Matlab software, and provide the basis for the construction of the coordinated development system of logistics economy and ecological environment in Anhui Province.

First of all, the data is preprocessed in a standardized way. However, the indicators selected in this paper include forward and reverse indicators, which must be calculated by classification. The mathematical formula is as follows:

$$
\begin{aligned}
& \chi_{i j}^{\prime}=\frac{\chi_{i j}-\min \left(\sum \chi_{j}\right)}{\max \left(\sum \chi_{j}\right)-\min \left(\sum \chi_{j}\right)}\left(\chi_{i j} \text { is the positive index }\right) \\
& \chi_{i j}^{\prime}=\frac{\max \left(\sum \chi_{j}\right)-\chi_{i j}}{\max \left(\sum \chi_{j}\right)-\min \left(\sum \chi_{j}\right)}\left(\chi_{i j} \text { is the inverse index }\right)
\end{aligned}
$$

Calculate the proportion of the i-th evaluation object in the J-th index, and replace 0 with 0.001 during the process, otherwise $\log (0)$ is prone to error.

$$
P_{i j}=\frac{X_{i j}}{\sum_{i=1}^{n} X_{i j}}(i=1,2 ; j=1,2, \cdots, n)
$$

The entropy value of the J-th index was calculated according to the characteristic proportion, and the difference coefficient $g_{j}$ of the index was obtained through formula (5). The larger the difference coefficient, the deeper the impact on the subsystem. The weight coefficient $w_{j}$ in the model was calculated by subputting the result into formula (6), so as to rank the main influencing factors of the synergy degree between logistics economy and ecological environment in Anhui Province.

$$
\begin{gathered}
c_{j}=-k \sum_{i=1}^{n} p_{i j} \ln \left(p_{i j}\right) \\
g_{i}=1-c_{j} \quad(j=1,2, \cdots, n) \\
w_{j}=\frac{g_{j}}{\sum_{j=1}^{m} g_{j}}(1 \leq j \leq m)
\end{gathered}
$$




\subsection{Maintaining the Integrity of the Specifications}

According to the weighting formula of entropy weight method, the index weights of order parameters of the two subsystems can be obtained. Among the 11 indicators selected by the logistics economic subsystem, the total amount of postal and telecommunications services and the added value of the logistics industry account for a larger proportion, 0.181 and 0.151 respectively, followed by the index of the proportion of the added value of the logistics industry in regional GDP, with a weight of 0.113 and the index of freight volume accounting for 0.098. Among the 10 indicators selected for the ecological environment subsystem, the total amount of industrial wastewater discharge and investment in environmental protection have a greater impact on the subsystem, with weights of 0.177 and 0.172 , respectively, followed by forest area and forest coverage rate. Therefore, Anhui Province in the development of logistics economy, to stimulate the social effective demand, improve the logistics activities of the business volume and information degree; When preventing and controlling environmental problems, we should pay attention to the treatment of waste water and waste gas in logistics enterprises, and appropriately increase the investment in pollution control.

$$
\begin{gathered}
W_{1 j}=(0.151,0.042,0.113,0.067,0.098,0.072,0.047,0.116,0.058,0.056,0.181) \\
W_{2 j}=(0.130,0.130,0.043,0.104,0.070,0.177,0.051,0.034,0.172,0.088)
\end{gathered}
$$

The weight coefficient is obtained to facilitate the calculation of the synergistic degree model of the composite system

\section{Empirical Analysis Sased on the Synergistic Degree Model of Composite System}

\subsection{Research Ideas}

The coordination model of composite system is mainly used to measure the coordination degree of composite system. The model is based on order parameters and servitude principle in synergetics to measure the degree of order of each element in the system and the degree of coordination between systems. At first, this paper respectively and the degree of order of logistics economic subsystem and environment subsystem, through a complex system coordination degree model to integrate both to the empirical analysis, get the logistics between economy and ecological environment as a result, the comprehensive coordination degree of discretion to study logistics coordination between economy and ecological environment system and judgment of the future development trend.

\subsection{Research Methods}

Assuming that logistics economic subsystem with $S_{1}$, ecological environment subsystem use $S_{2}$, the composite system is expressed as $S_{i}=\left\{S_{1}, S_{2}\right\}$ logistics economy and ecological environment, to $e_{i j}=\left\{e_{1 j}, e_{2 j}\right\}$ as the order parameter in the development of the two subsystems, including $j=1,2, \cdots, n$ says the 
number of order parameter index of each subsystem, $e_{i j}$ values in the range of $\alpha_{i j} \leq e_{i j} \leq \beta_{i j}, \beta_{i j}, \alpha_{i j}$, respectively the upper and lower bounds for value (Liu Yousheng \& Chen Dubin, 2016). When the order parameter $e_{i j}$ is a positive indicator, the larger its value is, the higher the order degree of the system will be; if not, the lower the order degree will be. The mathematical expression for calculating the order degree of the order parameter component of each subsystem is usually defined as follows. The greater the value of $u_{i}\left(e_{i j}\right) \in[0,1]$, the greater the contribution of order parameter to the order degree of subsystem is

$$
u_{i}\left(e_{i j}\right)=\left\{\begin{array}{l}
\frac{e_{i j}-\alpha_{i j}}{\beta_{i j}-\alpha_{i j}}\left(e_{i j} \text { is the positive index }\right) \\
\frac{\beta_{i j}-e_{i j}}{\beta_{i j}-\alpha_{i j}} \quad\left(e_{i j} \text { is the inverse index }\right)
\end{array}\right.
$$

In the total system of logistics economy and ecological environment, the method of integration and integration can be used to get the contribution degree of order parameters of each subsystem to the complex system. It is generally calculated by the weighted summation method, and its mathematical formula is shown as follows:

$$
u_{j}\left(e_{j}\right)=\sum_{j=1}^{n} w_{j} u_{i}\left(e_{i j}\right), w_{j} \geq 0, \sum_{j=1}^{n} w_{j}=1
$$

The value range of subsystem order degree is $u_{j}\left(e_{j}\right) \in[0,1]$, and the closer the value is to 1 , the higher the order degree of the system is. In the formula, $w_{j}$ refers to the weight of each order parameter index. Since the complex system of logistics economy and ecological environment is always in the dynamic development of constant changes, it is necessary to measure the interaction of each subsystem dynamically in different periods. Given the initial time $t_{0}, u_{j}^{0}\left(e_{j}\right)$ is the order degree of logistics economy subsystem and ecological environment subsystem respectively. When the order degree of logistics economy or ecological environment subsystem evolves into $u_{j}^{1}\left(e_{j}\right)$, it means that the whole system gradually develops to the time. If and only if $u_{j}^{1}\left(e_{j}\right) \geq u_{j}^{0}\left(e_{j}\right)$, then the value of the synergistic degree of the composite system in time period $\mathrm{T}$ is positive, and the whole composite system has positive synergistic effect.

$$
U=\lambda \sqrt{\left|\prod_{j=1}^{2}\left[u_{j}^{1}\left(e_{j}\right)-u_{j}^{0}\left(e_{j}\right)\right]\right|}, \lambda=\frac{\min _{j}\left[u_{j}^{1}\left(e_{j}\right)-u_{j}^{0}\left(e_{j}\right)\right]}{\left|\min _{j}\left[u_{j}^{1}\left(e_{j}\right)-u_{j}^{0}\left(e_{j}\right)\right]\right|}
$$

The value range of the synergistic degree of the composite system and its corresponding synergistic development degree are shown in Table 2.

\subsection{Result Analysis}

According to the model, the order degree of each subsystem of logistics economy and ecological environment from 2010 to 2018 is calculated, and on this basis, the synergy degree between logistics economy and ecological environment is obtained. The results are shown in Table 3. 
As can be seen from Figure 1, the order degree of logistics economic subsystem and ecological environment subsystem in Anhui Province showed an overall increasing trend year by year from 2010 to 2018. The maximum value of the synergy degree between the two was 0.1679 in 2018, and the minimum value was -0.0942 in 2013, which was always M-shaped and fluctuated in the range of

Table 2. Correspondence between value of synergy degree and development degree.

\begin{tabular}{cc}
\hline Value range of synergy degree & Degree of coordinated development \\
\hline$[-1,0.3)$ & No synergy or low level of synergy \\
{$[0.3,0.8)$} & Moderate cooperative state \\
{$[0.8,1)$} & Highly cooperative state \\
\hline
\end{tabular}

Table 3. Coordinated evaluation index system of logistics economy and ecological environment in Anhui Province

\begin{tabular}{cccc}
\hline Year & $\begin{array}{c}\text { Order degree } \\
\text { of logistics } \\
\text { economic subsystem }\end{array}$ & $\begin{array}{c}\text { Order degree of } \\
\text { ecological environment } \\
\text { subsystem }\end{array}$ & $\begin{array}{c}\text { Collaborative degree } \\
\text { of logistics economy and } \\
\text { ecological environment }\end{array}$ \\
\hline 2010 & 0.1089 & 0.2078 & - \\
2011 & 0.1562 & 0.2086 & 0.0060 \\
2012 & 0.2502 & 0.2320 & 0.0470 \\
2013 & 0.3924 & 0.1695 & -0.0942 \\
2014 & 0.4696 & 0.4572 & 0.1490 \\
2015 & 0.4881 & 0.4797 & 0.0204 \\
2016 & 0.6056 & 0.5714 & 0.1038 \\
2017 & 0.6396 & 0.7461 & 0.0771 \\
2018 & 0.9771 & 0.8297 & 0.1679 \\
\hline
\end{tabular}

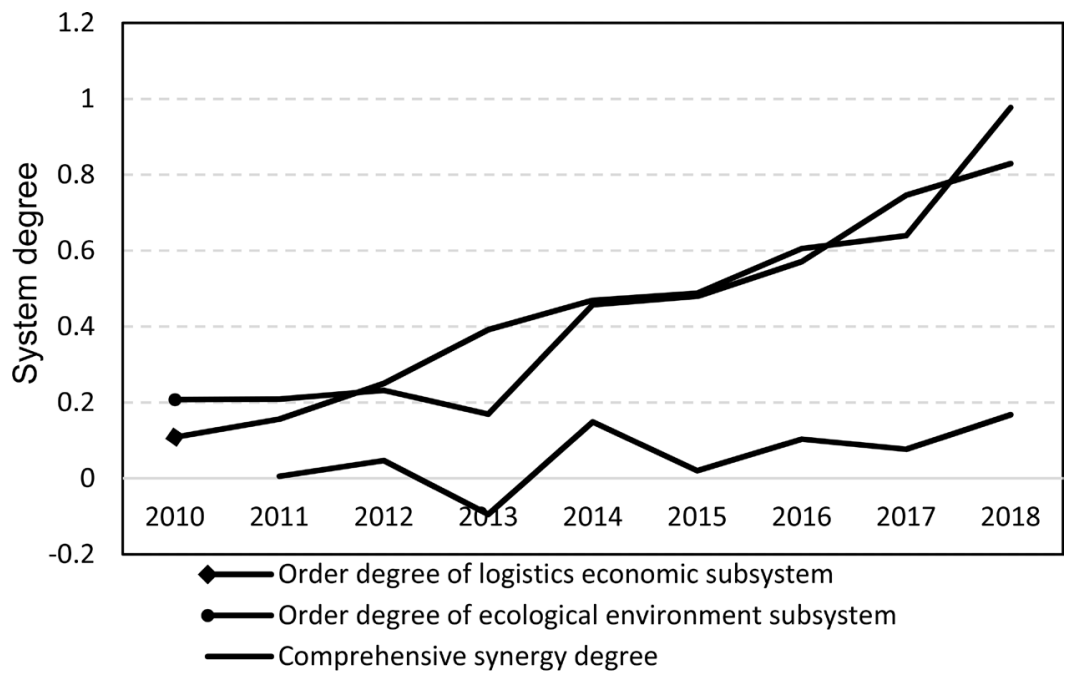

Figure 1. Collaborative trend of logistics economy and ecological environment in Anhui Province from 2010 to 2018. 
$[-0.2,0.2]$. The comparison Table 2 shows that there is a synergistic relationship between logistics economy and ecological environment system in Anhui Province, but the degree of development is different and it is still at a relatively low level.

It is mainly reflected in the non-synchronous development between logistics economy and ecological environment subsystem. With the continuous increase in the quantity and quality of modern logistics demand, various logistics facilities and equipment have been put into use in large quantities, but the adverse impact on the environment is increasingly prominent. Anhui Province officially launched the implementation of the "Anhui Province Modern Logistics Industry Development Plan" related policies and guidelines in 2010, the plan contains a series of measures to help the progress of the logistics industry: "pay attention to the development of agricultural products logistics, coal logistics, steel logistics, trade logistics and other key areas of logistics; Reduce the tax burden of logistics enterprises, increase the support to enterprises; Stimulate the standardization and informatization of the logistics industry, and build the generic technology service platform of the Internet of Things. Under the superimposed effect of the policy, the order degree of the subsystem in the logistics industry showed a rapid growth trend from 2011 to 2013. During this period, the increase of logistics operations and transportation distance resulted in severe air pollution. Anhui Provincial Environmental State Announcing pointed out that "the average number of days with good air quality in 2013 decreased by 9.9 percentage points compared with previous years". The order degree of ecological environment subsystem showed negative growth, and the order degree decreased by $2.69 \%$. Fortunately, the government made timely rectification and strengthened environmental law enforcement and inspection, which made the overall environmental quality of Anhui Province good in 2014 and formed a turning point for the improvement of air quality. The order degree of ecological and environmental subsystems increased again with the highest increase, rising to $16.97 \%$. While the environment is improving, it is affected by the macro environment. The global stock market crisis in summer and the lack of effective social logistics demand caused the development speed of the logistics industry in Anhui Province to slow down in 2015, the growth rate slowed down to $3.9 \%$.

The coordination degree of the composite system can be improved only when the subsystems develop in a balanced way. The advance or delay of any party will affect the coordination state of the composite system. For example, in 2014, the order degree of ecological environment subsystem caught up with the order degree of logistics economy subsystem, and the comprehensive synergy degree increased significantly with this change. In addition, if the development degree of two subsystems slows down synchronously, the comprehensive synergy degree of the whole system will also be affected. The difference of order degree between logistics economy and ecological environment subsystem was not large in 2015, but compared with the previous year, the development speed slowed down sig- 
nificantly, and the two were still difficult to effectively support and cooperate with each other, resulting in a low synergistic effect. However, when the order degree of subsystems develops in an opposite trend, it will lead to the instability of the synergistic degree of the composite system, which may decrease or increase, depending on the dominant subsystem. The state of the two subsystems gradually improved after 2015, and the comprehensive synergy degree showed an increasing trend in the future.

\section{Suggestions}

At present, the development trend of China's logistics industry is to transform to "green logistics with low pollution, low energy consumption and low emission", from the speed era to the era of green development. The logistics industry in Anhui Province also needs to keep up with the situation. While developing logistics economy and improving logistics service ability, it must take into account the orderly development of ecological environment.

The first point, the government has played a guiding role in creating a favorable environment for development. Clear the direction of the reform of logistics management system, implement unified management of all logistics activities of enterprises, and correctly exercise the function of green supervision, improve the waste charge system, require large logistics parks must build corresponding sewage treatment plants, to encourage enterprises to take the initiative to reduce waste water discharge, waste gas emission and noise pollution in logistics activities; Through tax policies to stimulate the logistics of enterprises to reduce resource energy consumption as far as possible. At the initial stage, high-intensity incentives will be implemented for large enterprises, and then the preferential policies will be extended to small and medium-sized enterprises and the incentive intensity will be reduced accordingly. The government will continue to increase investment in environmental governance and accelerate efforts to strengthen weak links in the ecological environment.

The second point, enterprises should play a leading role and improve their capacity for independent innovation. Accelerate technological innovation, effectively manage and use delivery vehicles, and use new energy vehicles on a large scale for short-distance intercity distribution. Using mathematical model method, scientific planning of cargo transport route, pay attention to the transport price and pay attention to the state of energy consumption; When transporting bulk goods, pay attention to airtight protection to avoid dust flying; Establish logistics information system, and conduct reasonable scheduling of logistics resources, such as carrying out joint distribution and developing third-party logistics; Minimize raw material consumption and waste discharge through environmentally friendly product design; Implement brand strategy, actively build green energy saving brand, implement enterprise logistics environment standard certification.

The third point, the public should take a long-term view and play a support- 
ing and supervising role. The direct victim of environmental pollution is the public. A clean public environment can improve the comfort of people's life. Therefore, the broad masses of society should actively respond to the circular economy model, start from me, enhance their own awareness of environmental protection, choose to buy recycled products, advocate "green consumption"; Active participation in garbage classification and recycling, to assist enterprises to implement reverse logistics; Exercise the right of public supervision, pay attention to the environmental changes caused by the non-standard logistics activities of enterprises, and express their aspirations through mass media, social groups or civil organizations.

\section{Acknowledgements}

This article is the research result of the College Student Scientific Research Innovation Fund of Anhui University of Finance and Economics, Project No: XSKY2188

\section{Conflicts of Interest}

The author declares no conflicts of interest regarding the publication of this paper.

\section{References}

Lan, S. L., \& Zhong, R. Y. (2018). Coordinated Development between Metropolitan Economy and Logistics for Sustainability. Resources, Conservation and Recycling, 128, 345354. https://doi.org/10.1016/j.resconrec.2016.08.017

Li, H., \& Li, L. (2019). Analysis on the Coordinated Development of Regional Logistics, Economic Growth and Ecological Environment. Statistics and Decision, 35, 143-145.

Liang, W., Chen, G. Q., Chai, Y. L., \& Sun, H. (2018). Research on the Coupling Coordination Degree of Regional Economy and Regional Logistics in Wanjiang Urban Belt. East Economic Management, 32, 78-86.

Liu, Y. S. Chen, D. B. (2016). Analysis of Cross-Border E-Commerce and Modern Logistics Collaborative Evaluation Based on Complex System Collaborative Degree Model. China Circulation Economy, 30, 106-114

Lu, Q. H., \& Liu, W. (2020). Research and Analysis on Teaching Contest of University Teachers Based on Entropy Weight Method and TOPSIS Method. Journal of Shandong University (Natural Science Edition), 36, 312-320.

Xia, Y. L., He, G., \& Wang, W. W. (2017). Evaluation of Synergistic Degree of Eco-Economic System in Resource-Based Cities Based on the Synergistic Degree Model of Composite System. Journal of Anhui University of Science and Technology (Social Science Edition), 19, 44-51 